\title{
Neurogenically Mediated Leakage of Plasma Protein Occurs from Blood Vessels in Dura Mater But Not Brain
}

\author{
Stephen Markowitz, Kiyoshi Saito, and Michael A. Moskowitz \\ Stroke Research Laboratory, Massachusetts General Hospital, Harvard Medical School, Boston, Massachusetts 02114
}

Utilizing ${ }^{125} \mid-B S A$ administered intravenously, a simple, reliable, and sensitive method was established for the detection of plasma protein extravasation in the dura of rats and guinea pigs following chemical, electrical, or immunological stimulation. Extravasated ${ }^{125}$-BSA or Evans blue was noted in the dura and conjunctiva but not in the temporalis muscle of saline-perfused rats following intravenous capsaicin, 1 $\mu \mathrm{mol} / \mathrm{kg}$. Capsaicin-induced extravasation was mediated by unmyelinated and small myelinated fibers since leakage did not develop in adult animals in whom these fibers were destroyed by capsaicin pretreatment $(50 \mathrm{mg} / \mathrm{kg})$ as neonates. An ipsilateral increase in Evans blue and ${ }^{125}$-BSA was found in the dura, eyelids, lips and gingival mucosa, and snout following electrical stimulation of the rat trigeminal ganglion. This increase was also C-fiber dependent. Among those peptides contained in perivascular afferent fibers and administered intravenously, substance $P$ (SP) and neurokinin A (NKA), but not calcitonin gene-related peptide, caused a dose-dependent extravasation in the dura and conjunctiva of rats. Neonatal capsaicin pretreatment did not attenuate SP- nor NKA-induced effects in the dura and actually increased extravasation in the conjunctiva. Intravenous administration of 5-HT or bradykinin to normal adult rats or adult rats pretreated as neonates with capsaicin increased levels of ${ }^{125}$-BSA in both the dura and the conjunctiva. Histamine and prostaglandin $E_{2}$, on the other hand, caused protein leakage in the conjunctiva but not in the dura of rats; however, histamine did induce extravasation in the dura of guinea pigs. Ovalbumin challenge to previously sensitized guinea pigs produced marked dural and conjunctival extravasation, which was significantly reduced by combined $\mathrm{H1}$ and $\mathrm{H}_{2}$ histamine receptor blockade. Participation of $\mathrm{C}$ fibers was suggested by the finding that capsaicin desensitization diminished the increase in permeability by $58 \%$ in the dura and $30 \%$ in the conjunctiva. This reduction was not statistically significant, however. Extravasation was not observed in the brain following chemical, electrical, or immunological stimulation nor following topical application of capsaicin to the pial surface or injection into the cortex of rats. The implications of neurogenically mediated dural plasma extravasation for the pathophysiology of vascular head pain are discussed.

\footnotetext{
Received Mar. 9, 1987; revised June 3, 1987; accepted June 5, 1987.

This work was supported by grants from the National Institute of Neurological and Communicative Disorders and Stroke (NS 21558, NS 10828).

Correspondence should be addressed to Michael A. Moskowitz, Stroke Research Laboratory, Wellman 423, Massachusetts General Hospital, Fruit Street, Boston, MA 02114.

Copyright (C) 1987 Society for Neuroscience $0270-6474 / 87 / 124129-08 \$ 02.00 / 0$
}

Plasma extravasation and vasodilation are major components of the inflammatory response that may develop by neurogenic or non-neurogenic mechanisms. The phenomenon that has become known as neurogenic inflammation accompanies antidromic electrical stimulation of sensory nerves or follows mechanical or chemical stimulation of these same fibers (Stricker, 1876; Jancso et al., 1967; Lembeck and Holzer, 1979). Capsaicin [8-methylnonene-(6)-oyl vanillylamide], the active ingredient of hot peppers, depolarizes sensory axons and releases vasodilating and permeability-promoting transmitters from perivascular afferent axons with the consequent development of neurogenic inflammation (Hua et al., 1986; Saria et al., 1986). Non-neurogenic plasma extravasation can be induced by the intravenous administration of substances such as $5-\mathrm{H}^{\mathrm{l}} \mathrm{l}$, histamine, and bradykinin (BK) (Gabbiani et al., 1970; Saria et al., 1983), which directly alter blood vessel permeability. The cndothclium at postcapillary venules is the postulated target for the mediators of both neurogenic and non-neurogenic plasma extravasation (Majno and Palade, 1961; Majno et al., 1961; Kenins et al., 1984; Miller and Sims, 1986).

Neurogenic inflammation is an important endogenous defense mechanism and provides one of the earliest tissue responses to local injury, accelerating and modulating the development of the inflammatory process. Enhanced blood flow and leakage of plasma constituents protects against noxious substances by diluting and clearing such chemicals, as occurs with the more slowly developing cellular response typical of other types of inflammation. Neurogenic inflammation has been observed in a number of tissues at portals of entry-including the integument (Jancso et al., 1967; Kenins et al., 1984), the respiratory tract (Lundberg and Saria, 1982), the genitourinary tract (Hua et al., 1986), and parts of the digestive tract (Saria et al., 1983; Lundberg et al., 1984)-further emphasizing its likely role as an endogenous defense mechanism. Neurogenic inflammation occurs almost exclusively in those tissues possessing substance $\mathrm{P}(\mathrm{SP})$-containing unmyelinated sensory fibers innervating blood vessels (Saria et al., 1983; Lundberg et al., 1984) and can be attenuated by SP receptor blockers (Rosell et al., 1981) or drugs that inhibit the relcasc of SP from thesc fibers (Lembeck et al., 1982; Lembeck and Donnerer, 1985). However, recent work suggests that neurokinin A (NKA), a related tachykinin, may also be important, since both SP and NKA reside in the same sensory fibers (Dalsgaard et al., 1985), are released upon depolarization (Saria et al., 1986), and are potent vasodilators and enhancers of vascular permeability (Hua et al., 1984). CGRP, a peptide also found in primary sensory fibers (Hanko et al., 1985), is a potent vasodilator (Brain et al., 1985) that demonstrates no intrinsic effects on permeability (Gamse and Saria, 1985). 
The discovery of the trigeminal innervation of the intracranial pial (Mayberg et al., 1981, 1984) and dural vessels (Von Lushka, 1850; Steiger et al., 1982; Mayberg et al., 1984; O'Connor and van der Kooy, 1986) and the demonstration of neurogenic inflammation in extracranial areas of trigeminal innervation (Jancso-Gabor and Szolcsanyi, 1972; Lundblad et al., 1983a, b; Couture and Cuello, 1984; Lundberg et al., 1984) suggested the possibility that neurogenic inflammation might also develop within pain-sensitive intracranial structures. We have therefore examined this possibility in the dural and pial vasculatures following depolarization of sensory afferent fibers and have postulated that neurogenic inflammation may be important in the pathogenesis of headache. In this regard, the dura represents a particularly attractive locus. It is one of a few intracranial structures that cause pain upon stimulation (Ray and Wolff, 1940) and contains the structures important for the development of neurogenic inflammation: blood vessels that are surrounded by a network of finely myelinated and unmyelinated fibers (McNaughton, 1938) and a large number of mast cells (Olsson, 1968; Edvinsson et al., 1977).

\section{Materials and Methods}

Materials. Drugs and chemicals used included 5-HT, histamine, prostaglandin $\mathrm{E}_{2}\left(\mathrm{PGE}_{2}\right)$, cimetidine, mepyramine (pyrilamine), Evans blue, and formamide (Sigma Chemical Co., St. Louis, MO); capsaicin (Signia or Polysciences, Warrington, PA); BK (Bachem, Torrence, CA); SP, NKA, CGRP (Peninsula Laboratories, San Carlos, CA). ${ }^{125}$ I-BSA (specific activity, $1.3-2.52 \mu \mathrm{Ci} / \mu \mathrm{g}$ ) was purchased from New England Nuclear (Boston). Capsaicin was prepared from a stock solution $(3 \mathrm{mg} / \mathrm{ml}$ in vehicle, 10:10:80/Tween 80:ethanol: saline) and kept at $4^{\circ} \mathrm{C}$. Stock solutions of SP, BK, CGRP ( $0.01 N$ acetic acid), NKA ( $2 N$ acetic acid), and histamine $(0.01 \mathrm{~N} \mathrm{HCl})$ were frozen in aliquots and stored at $-70^{\circ} \mathrm{C}$. Other substances were made up fresh at the time of experimentation $\mathrm{SP}, 5-\mathrm{HT}, \mathrm{PGE}_{2}$, and Evans blue were dissolved in normal saline; NKA CGRP, histamine, and $\mathrm{BK}$ in PBS, $\mathrm{pH} 7.4$; cimetidine and mepyramine in $5 \%$ dimethyl sulfoxide.

Chemically induced changes in vascularpermeability. Sprague-Dawley rats (150-250 gm, Charles River Laboratories, Wilmington, MA) were maintained in normal diumal lighting and allowed access to food and water ad libitum. To test the ability of chemicals to induce extravasation, anesthetized rats (pentobarbital $60 \mathrm{mg} / \mathrm{kg}$, i.p.) were injected with 100 $\mu \mathrm{Ci} / \mathrm{kg}^{125} \mathrm{I}$-BSA $(100 \mu \mathrm{Ci} / \mathrm{ml}$ saline) and $50 \mathrm{mg} / \mathrm{kg}$ Evans blue $(50 \mathrm{mg} /$ $\mathrm{ml}$ saline) via the left femoral vein. Five minutes later, one of the following chemicals $(1 \mathrm{ml} / \mathrm{kg})$ was administered via the opposite femoral vein; capsaicin, neuropeptides, 5-HT, BK, histamine, or $\mathrm{PGE}_{2}$. Control animals received either saline, $\mathrm{PBS}$, or capsaicin vehicle. Artificial ventilation was provided via an 18 gauge tracheal cannula by a small animal respirator (Model 683, Harvard Instruments, South Natick, MA) during the transient respiratory impairment caused by high doses of capsaicin, 5-HT, or BK. Tracheostomy alone proved adequate for the aspiration of excessive mucous secretions caused by the administration of high doses of SP and NKA.

Fifteen minutes after injecting tracer, and 10 minutes after drug injection, the thorax was opened, the descending aorta clamped, and the right atrium incised for drainage. Saline was perfused via the left ventricle at a constant pressure of $120 \mathrm{~mm} \mathrm{Hg}$ for $2 \mathrm{~min}$. Saline perfusion flushed all the blood from the intravascular compartment but did not remove extravasated dye. None of the drug treatments reduced the efficiency of intracranial perfusion. Following removal of the brain, the cranial cavity was thoroughly rinsed prior to dissection of the dura. The following tissues were routinely dissected, weighed, and counted for 20 min in a Micromedic 4/600 gamma counter (Micromedic, Philadelphia): the conjunctivae on both sides, a piece of temporalis muscle, the dura covering the forebrain, and a mantle of frontoparietal cortex. To extract extravasated Evans blue, the dissected tissues were incubated in $2 \mathrm{ml}$ formamide at $55^{\circ} \mathrm{C}$ overnight. Colorimetric measurements were performed on a Beckman DU-6 spectrophotometer (Irvine, CA) at the absorption maximum for Evans blue, $620 \mathrm{~nm}$. Fluorescence measurements were performed on a spectrofluorometer (model 430, Turner, Mt. View, CA) at an excitation wavelength of $620 \mathrm{~nm}$ and an emission wavelength of $680 \mathrm{~nm}$ as previously described (Saria and Lundberg, 1983). Evans blue content was calculated by linear regression analysis from external standards prepared in formamide. Formamide incubated with tissue (without injection of Evans blue) did not demonstrate increased absorption at $620 \mathrm{~nm}$.

Pial application and cortical injection of capsaicin. In adult rats, bilateral burr holes were drilled over the parietal cortex, the dura incised, and pial surfaces exposed. Five minutes prior to drug application, Evans blue, $15 \mathrm{mg} / 0.5 \mathrm{ml}$ saline, was injected into the femoral vein. Capsaicin $(0.05-50 \mu \mathrm{g} / 5 \mu \mathrm{l})$ or an equal volume of vehicle was applied topically to the underlying pial surface on each side. Extravasation was assessed qualitatively with the aid of a dissecting microscope $(\times 50)$.

In a second serics of expcriments, the above protocol was followed except that $30 \mathrm{~min}$ prior to intracortical capsaicin injection, Evans blue was administered. Capsaicin $(0.01-30 \mu \mathrm{g} / 3 \mu \mathrm{l})$ and vehicle were injected over $60 \mathrm{~min}$ under stereotactic control into the left and right side (respectively) of the cortex at a depth of $1.5 \mathrm{~mm}$ below the pial surface. Rats were then decapitated, and the brains removed, frozen, and sectioned coronally. The Evans blue content was qualitatively assessed and compared on the 2 sides with the aid of a dissecting microscope $(\times 50)$.

Electrical stimulation of the trigeminal ganglion. Anesthetized animals (pentobarbital, $55 \mathrm{mg} / \mathrm{kg}$ ) were placed in a small animal stereotaxic apparatus (model 900, David Kopf Instruments, Tujunga, CA). Two burr holes (1-2 mm diameter) were drilled on each side at the following coordinates with respect to the intersection of the coronal and sagittal sutures: $-1.2,2.5$ and $-3.2,2.5$. Animals than received ${ }^{125}$ I-BSA and Evans blue via the left femoral vein as described above. Paired nonconcentric bipolar electrodes (Rhodes NE-200, Woodland Hills, CA) were lowered under stereotactic control to a depth of $9.8-10.2 \mathrm{~mm}$ below the surface of the calvarium, ensuring bilateral placement in the trigeminal ganglia. The left or right side was arbitrarily designated for stimulation. The test side was stimulated consecutively for $5 \mathrm{~min}$ at the 2 sites using paired rectangular pulses of opposite polarity with 5 pulses/ $\mathrm{sec}$ of $5 \mathrm{msec}$ duration, at an intensity of $3.0 \mathrm{~mA}$ [WPI Microstim III (microprocessor) and WPI Iso Linear III (current generator), World Precision Instruments, New Haven, CT]. The current delivered and the potential difference across the electrode $(20-30 \mathrm{~V})$ was monitored using an oscilloscope (Hitachi model V-134, Hitachi Denshi, Tokyo). Correct electrode placement was indicated by ipsilateral contraction of the muscles of mastication during stimulation. After the period of electrical stimulation ( $10 \mathrm{~min}$ total), animals were sacrificed by saline perfusion as described above. The following tissues were routinely dissected and analyzed for radioactivity and Evans blue as described above: the eyelids and a rim of attached conjunctiva, the upper and lower lips and attached gingival mucosa, a mantle of frontoparietal cortex, the snout, a discoid area containing the vibrissae, and the dura (excluding that area damaged by the passage of the electrodes). Stimulation sites were verified at post mortem with the aid of a dissecting microscope.

Neonatal capsaicin pretreatment. Some animals were pretreated within the first $48 \mathrm{hr}$ of life with capsaicin, $50 \mathrm{mg} / \mathrm{kg}$ s.c., or vehicle as previously described (Jancso et al., 1977).

Allergy-induced extravasation. Hartley guinea pigs $(300-400 \mathrm{gm}$, Charles River) were sensitized by a single intraperitoneal injection of 1 $\mu \mathrm{g}$ ovalbumin and $100 \mathrm{mg} \mathrm{Al}(\mathrm{OH})_{3}$ in $0.5 \mathrm{ml}$ saline as described by Andersson (1980). Four to six weeks following sensitization, animals were anesthetized with pentobarbital $(50 \mathrm{mg} / \mathrm{kg}$ i.p.), injected with Evans blue $(50 \mathrm{mg} / \mathrm{kg})$ and ${ }^{125} \mathrm{I}-\mathrm{BSA}(50 \mu \mathrm{Ci} / \mathrm{kg})$, and $5 \mathrm{~min}$ later challenged with intravenous injection of $20 \mu \mathrm{g} / \mathrm{kg}$ ovalbumin. Ten minutes after ovalbumin challenge, the animals were perfused with saline and tissues dissected as described above. Age- and weight-matched nonsensitized guinea pigs were also challenged with $20 \mu \mathrm{g} / \mathrm{kg}$ ovalbumin. To determine the capsaicin-sensitive fiber dependence, some adult animals were pretreated with capsaicin, $125 \mathrm{mg} / \mathrm{kg}$ total, in divided doses in the week prior to challenge. Under light pentobarbital anesthesia $(30 \mathrm{mg} / \mathrm{kg})$ and isoproterenol nebulization, capsaicin was administered subcutaneously in incremental doses $(1,4,10,20,40$, and $50 \mathrm{mg} / \mathrm{kg})$ over a $3 \mathrm{~d}$ period. To examine for the possibility of histamine mediation, some guinea pigs received cimetidine, $10 \mathrm{mg} / \mathrm{kg}$, and mepyramine, $10 \mathrm{mg} / \mathrm{kg}$ i.p., 25 $\mathrm{min}$ before challenge with ovalbumin, $20 \mu \mathrm{g} / \mathrm{kg}$ i.v. In other experiments, the effect of histamine $(1 \mu \mathrm{mol} / \mathrm{kg})$ was tested by intravenous injection. Only conjunctiva and dura were routinely analyzed, though brain was also examined for the presence of extravasation in initial experiments.

Data. ${ }^{125}$ I-BSA data (mean \pm SEM) are expressed either as $\mathrm{cpm} / \mathrm{mg}$ wet weight or as a percentage of the control values in the case of chem- 


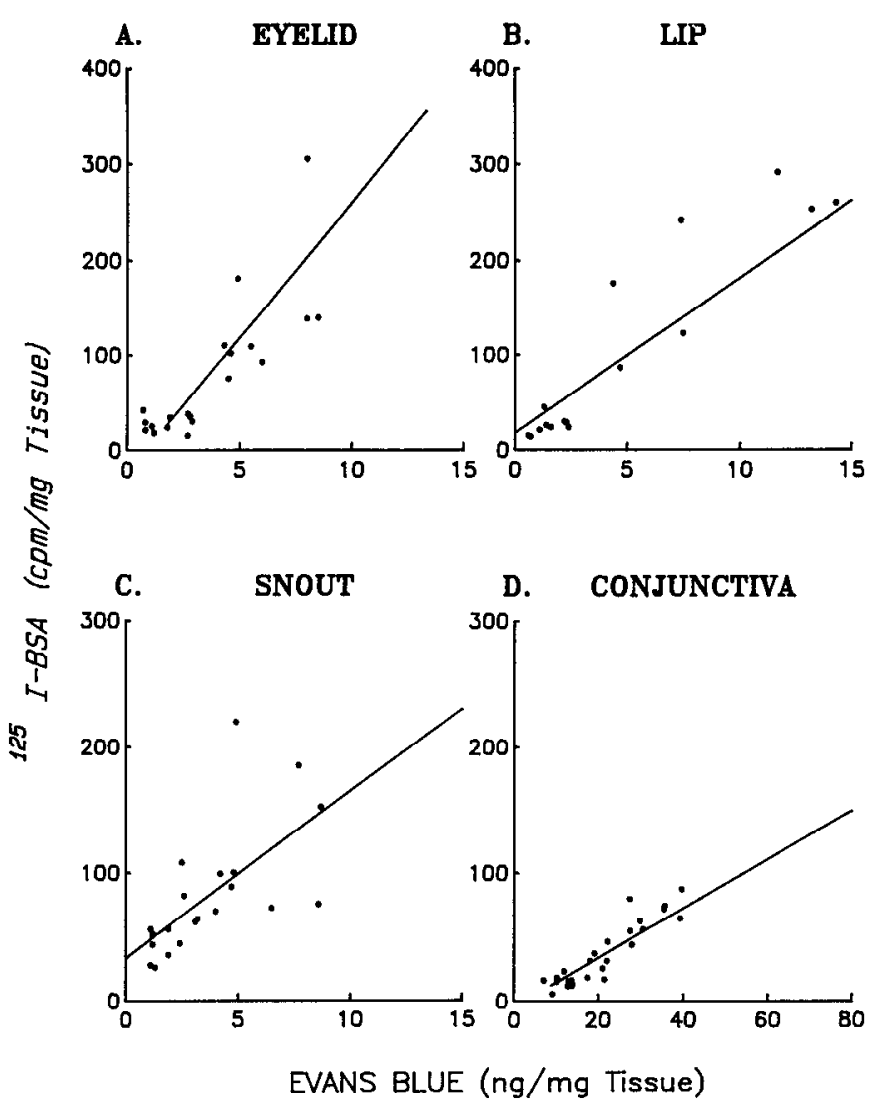

Figure 1. Correlation between extravasated Evans blue (ng/mg wet weight) and ${ }^{125} \mathrm{I}-\mathrm{BSA}$ (cpm/mg wet weight) in eyelid $(A, R=0.94)$, lip ( $B, R=0.86)$, snout $(C, R=0.65)$, and conjunctiva $(D, R=0.94)$ of rats following electrical $(A-C)$ or chemical $(D)$ stimulation. The correlation cocfficients in each tissuc are statistically significant $(p<0.01)$.

ically induced extravasation. Extracted Evans blue is expressed as $\mathrm{ng} /$ $\mathrm{mg}$ wet weight. Statistical significance was assessed by Student's $t$ test. Correlation coefficients were calculated by regression analysis. Probability values of less than 0.05 were considered significant.

\section{Results}

The dura weighed approximately $10-20$ and $20-30 \mathrm{mg}$ in the rat and guinea pig, respectively. The amount of Evans blue extracted from dura was below the assay sensitivity (100 ng/ $\mathrm{ml}$ ) in all vehicle-injected and some chemical-injected animals. The amount of isotope, however, was readily detected in those animals. Hence, for experiments in which the dura was to be examined, ${ }^{125}$ I-BSA was always used as a tracer. In all other extracranial tissues, the extracted Evans blue was well above assay sensitivity. There was a good correlation between the content of Evans blue and ${ }^{25}$ I-BSA, as evidenced in those extracranial tissues in which Evans blue was reliably detected-conjunctiva, eyelid, snout, and lip (Fig. 1).

\section{Chemically induced protein leakage in intracranial tissues}

SP, NKA, 5-HT, and BK caused extravasation in the dura (Fig. 2). The threshold dose for SP was $0.1 \mathrm{nmol} / \mathrm{kg}$; for NKA, 1 $\mathrm{nmol} / \mathrm{kg}$; and for $5-\mathrm{HT}$ and BK, $0.1 \mu \mathrm{mol} / \mathrm{kg}$. The largest response was approximately $150-200 \%$ of control. The threshold dose for capsaicin $(1 \mu \mathrm{mol} / \mathrm{kg})$ caused an increase of $125 \%$ of control. At higher doses $(3.0 \mu \mathrm{mol} / \mathrm{kg})$, capsaicin compromised cardiopulmonary function and proved lethal in the majority of
A. DURA

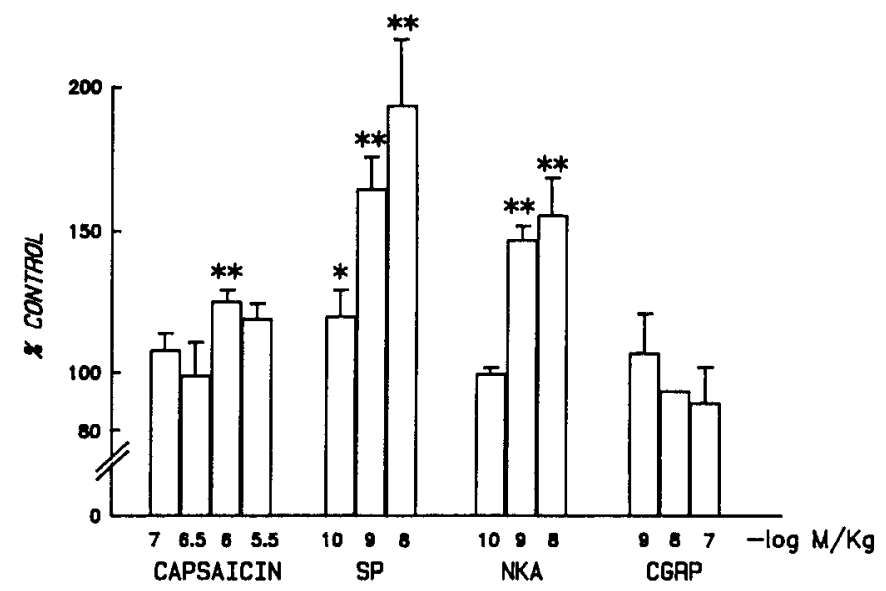

B.

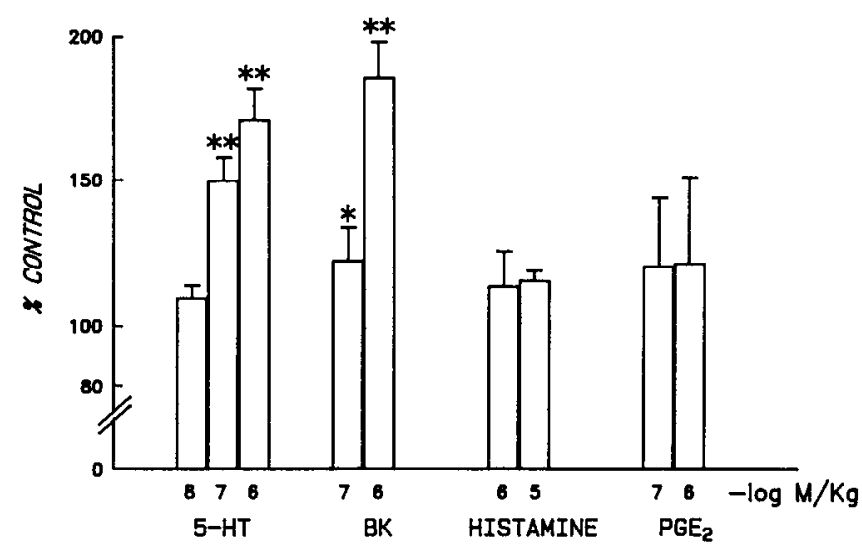

Figure 2. Extravasation of ${ }^{125}$ I-BSA into the rat dura follows the intravenous injection of capsaicin, SP, NKA, 5-HT, or BK but not CGRP, histamine, or $\mathrm{PGE}_{2}$. Data represent the means of 3-21 animals in each group and are expressed as a percentage of saline, PBS, or capsaicin vehicle-injected controls. Control groups do not differ statistically from one another: mean, $7.2 \pm 1.0 \mathrm{cpm} / \mathrm{mg}$ wet weight. ${ }^{*} p<0.05,{ }^{* *} p<$ 0.01 as compared to control.

cases. In 1 out of 5 experiments, the capsaicin-induced plasma extravasation $(1 \mu \mathrm{mol} / \mathrm{kg}$ ) was not observed in the dura, although extravasation was present in the extracranial tissues. A fresh solution of capsaicin was made, which usually restored the response in the dura of subsequently tested animals. Even at the highest dose, CGRP $(0.1 \mu \mathrm{mol} / \mathrm{kg})$, histamine $(10 \mu \mathrm{mol} / \mathrm{kg})$, and $\mathrm{PGE}_{2}(1 \mu \mathrm{mol} / \mathrm{kg})$ did not increase ${ }^{125}$ I-BSA levels in the dura. In guinea pigs, however, albumin leakage developed in the dura following histamine injection $(1 \mu \mathrm{mol} / \mathrm{kg}$ ) (Fig. 6). Neither CGRP nor PGE $_{2}$ were tested in this species.

Levels of isotope never increased above control values in cortical brain tissue after treatment with the chemicals noted above (Table 1). Indeed, even the topical application of capsaicin to the pial surface or direct injection into the cortex did not cause extravasation.

\section{Chemically induced protein leakage in extracranial tissues}

Intravenous capsaicin, SP, NKA, BK, 5-HT, histamine, and $\mathrm{PGE}_{2}$ evoked a dose-dependent extravasation of plasma protein in the conjunctiva (Fig. 3). Of these 7 compounds, SP was the 
A.

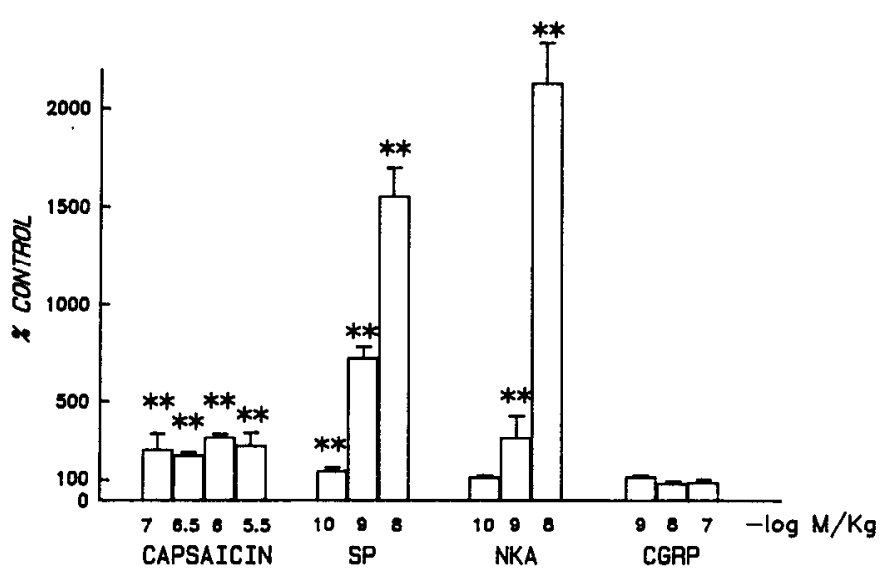

B.

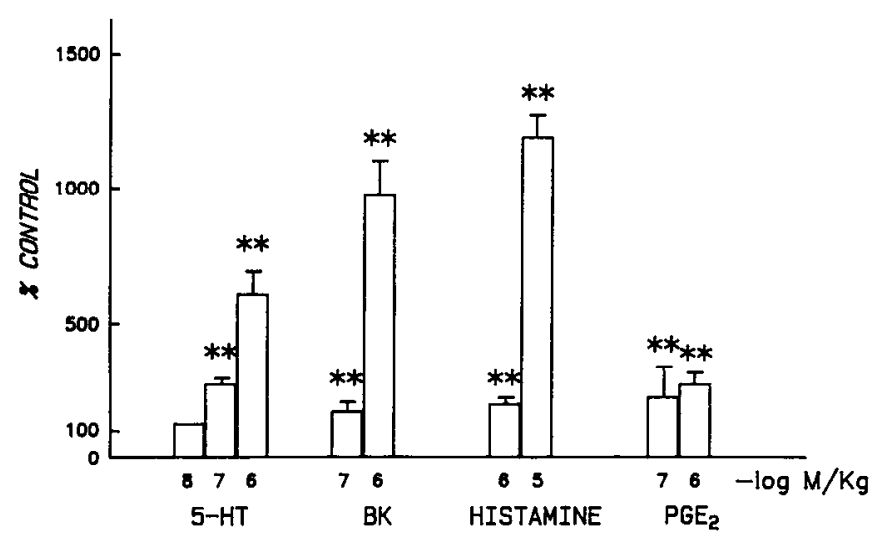

Figure 3. Extravasation of ${ }^{125}$ I-BSA into the rat conjunctiva follows the intravenous injection of capsaicin, SP, NKA, 5-HT, BK, histamine, or $\mathrm{PGE}_{2}$ but not CGRP. Data represent the means of 3-18 animals in each group and are expressed as a percentage of vehicle-injected controls (see legend to Fig. 2). Control groups did not differ statistically from one another: mean $15.0 \pm 1.0 \mathrm{cpm} / \mathrm{mg}$ wet weight. ${ }^{* *} p<0.01$ as compared to control.

most potent; CGRP had no effect. The thresholds were as follows: SP, $0.1 \mathrm{nmol} / \mathrm{kg}$; NKA, $1 \mathrm{nmol} / \mathrm{kg}$; $5 \mathrm{HT}$, BK, and $\mathrm{PGE}_{2}$, $0.1 \mu \mathrm{mol} / \mathrm{kg}$; and histamine, $1 \mu \mathrm{mol} / \mathrm{kg}$. The threshold dose for capsaicin was not determined in the conjunctiva but was less than $0.1 \mu \mathrm{mol} / \mathrm{kg}$. The response order was NKA $>\mathrm{SP}>$ histamine $\geq \mathrm{BK}>5-\mathrm{HT}>\mathrm{PGE}_{2}=$ capsaicin. Plasma extravasation was about an order of magnitude greater in the conjunctiva than in the dura with all agents.

Extravasation was detected in temporalis muscle but only after administering high doses of histamine $(10 \mu \mathrm{mol} / \mathrm{kg}), 5-\mathrm{HT}$, BK $(1 \mu \mathrm{mol} / \mathrm{kg})$, or NKA $(10 \mathrm{nmol} / \mathrm{kg})($ Table 1$)$.

\section{Effect of neonatal capsaicin pretreatment on chemically induced extravasation}

Capsaicin induced extravasation did not develop in the dura and was significantly reduced in the conjunctiva of adult rats treated as neonates with capsaicin. However, the response in the dura to intravenously administered SP, NKA, 5-HT, and BK did not differ between those animals and their littermates treated with vehicle or age-matched controls. Rather, an in-
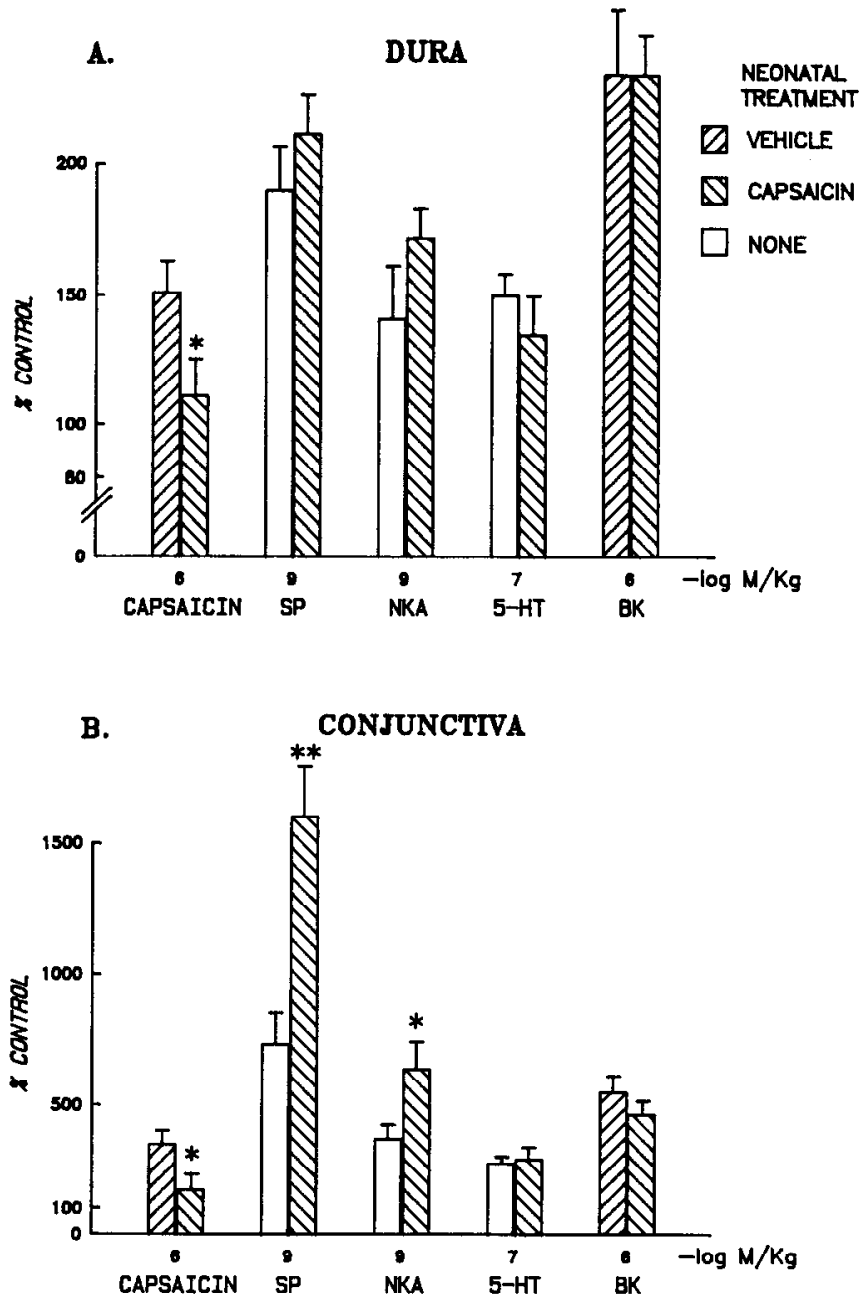

Figure 4. Neonatal capsaicin treatment blocks or attenuates the extravasation in the dura $(A)$ or the conjunctiva $(B)$ induced by intravenous injection of capsaicin, but not by SP, NKA, 5-HT, or BK. Capsaicin pretreatment enhances the response to SP or NKA in the conjunctiva. ${ }^{*} p<0.05,{ }^{* *} p<0.01$ compared to neonatal vehicle-treated or agematched animals. $n=4-8$ in each group.

creased amount of extravasation was measured in the conjunctiva after injecting SP and NKA but not 5-HT or BK (Fig. 4).

\section{Effect of electrical stimulation}

Extravasation occurred in all animals tested. A distinct blue discoloration developed within the dermatome of the ipsilateral trigeminal nerve in the first minute of stimulation. After several minutes, tissues turned a deep blue, and there was obvious edema of the eyelids, lips, and ala nasi. Edematous swelling and an enhanced coloration was also observed in the nasal mucosa. The oral cavity consistently revealed marked staining of the ipsilateral upper anterolateral gingival mucosa, with a lesser extent in the soft palate. In about $50 \%$ of cases, there was unilateral blueing of the mucosa on the inferior aspect of the tongue. Associated with the tissue blueing, there was copious clear salivation and, less frequently, a watery, blue mucous secretion from the ipsilateral external naris.

Extravasation of ${ }^{125}$ I-BSA was significantly higher in the dura on the stimulated side. Similar effects were found in extracranial tissues. In brain, however, the amount of isotope was identical 


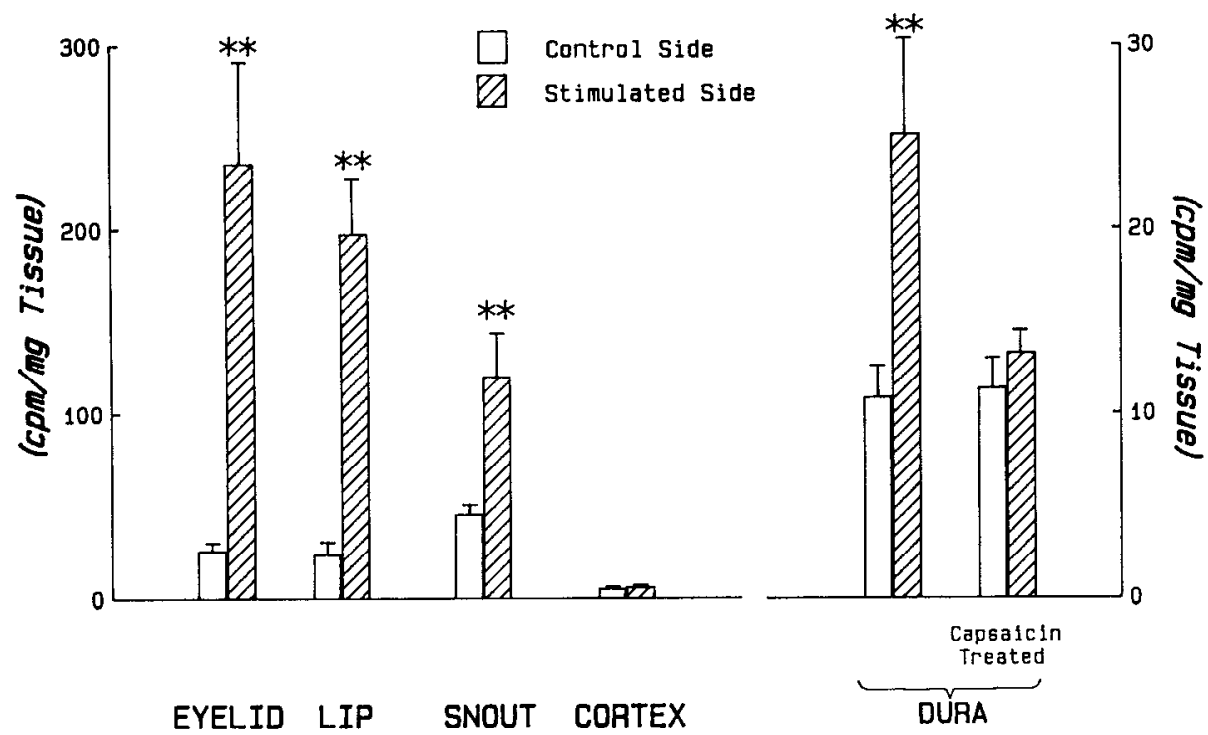

Figure 5. Electrical stimulation of the rat trigeminal ganglion increases the content of ${ }^{225}$ I-BSA in innervated tissues. Bipolar electrodes were placed in both trigeminal ganglia and stimulation delivered to one side $(3 \mathrm{~mA}, 5 \mathrm{~Hz}$, for 5 min at each of the 2 sites). The value for cortex on the stimulated side, mean $5.9 \pm 0.8$, did not differ from the nonstimulated side, mean $5.2 \pm 0.9$. $n=$ 10. ${ }^{* *} p<0.01$ as compared to the unstimulated side. Neonatal capsaicin treatment blocks the extravasation in the dura on the stimulated side as compared to neonatal vehicle-treated rats. $n=6 ; p<0.05$. on both sides. The electrically induced extravasation was abolished in the dura of those animals treated neonatally with capsaicin (Fig. 5).

\section{Effect of antigenic challenge}

Antigenic challenge of presensitized guinea pigs caused significant dural and conjunctival extravasation (Fig. 6). Antigen-induced extravasation was not found in brain: $0.68 \pm 0.09 \mathrm{cpm} /$ $\mathrm{mg}$ wet weight and $0.71 \pm 0.08 \mathrm{cpm} / \mathrm{mg}$ wet weight for nonsensitized and sensitized animals, respectively. Combined administration of $\mathrm{H} 1$ and $\mathrm{H} 2$ antagonists (both $10 \mathrm{mg} / \mathrm{kg}$ i.p.) $25 \mathrm{~min}$ prior to experimentation significantly reduced the response in the dura and conjunctiva $(p<0.05)$. Capsaicin desensitization of adult animals diminished the response to antigenic challenge by $58 \%$ in the dura and by $30 \%$ in the conjunctiva, although these reductions were not statistically significant ( $p \geq 0.10$ and 0.30 , respectively).

\section{Discussion}

\section{Neurogenically mediated plasma extravasation}

Neurogenically mediated plasma extravasation induced electrically or chemically has been demonstrated previously in oral, nasal, facial, and ocular tissues, that is, tissues receiving a trigeminal innervation (Jancso-Gabor and Szolcsanyi, 1972; Bill et al., 1979; Lundblad et al., 1983b; Saria et al., 1983; Couture and Cuello, 1984; Lundberg et al., 1984). We have now shown that plasma extravasation develops by neurogenic mechanisms within the dura following chemical (capsaicin) or electrical stimulation and have confirmed that it does not occur within brain. The demonstration that neonatal capsaicin treatment abolishes the extravasation evoked by intravenous capsaicin and electrical stimulation emphasizes and confirms the neurogenic basis of this response (Jansco et al., 1977; Gamse et al., 1980). The ability to quantitate the plasma extravasation in the dura was facilitated by the enhanced sensitivity afforded by the use of ${ }^{125}$ I-BSA. The strong correlation between the 2 tracers in peripheral tissues suggests that the isotopic technique reflects plasma extravasation in much the same way as Evans blue, and it validates comparison with previous work based on the Evans blue technique. Though reliable quantitation of Evans blue was not possible in the dura, the presence of Evans blue outside the vascular compartment was confirmed by fluorescence microscopy in dural whole-mount preparations (data not shown).

Important differences were detected in tissues innervated by the trigeminal nerve. The amount of plasma extravasation was significantly less in dura than in other tissues examined. Furthermore, the thresholds for capsaicin or electrical stimulation were significantly higher in dura. By contrast, the brain never

Table 1. ${ }^{125}$ I-BSA (cpm/mg wet weight) in the cortex and the temporalis muscle following intravenous injection of capsaicin or vasoactive substances

\begin{tabular}{lclc} 
Chemicals & $\begin{array}{c}\text { Dose } \\
(-\log \\
M / \mathrm{kg})\end{array}$ & Cortex & $\begin{array}{l}\text { Temporalis } \\
\text { muscle }\end{array}$ \\
\hline Control & - & $0.68 \pm 0.03$ & $4.2 \pm 0.5$ \\
Capsaicin & 7 & $0.70 \pm 0.13$ & $4.6 \pm 0.4$ \\
& 6.5 & $0.58 \pm 0.08$ & $4.2 \pm 0.2$ \\
& 6 & $0.69 \pm 0.05$ & $4.9 \pm 0.3$ \\
Substance P & 5.5 & $0.63 \pm 0.11$ & \\
& 10 & $0.73 \pm 0.10$ & $4.2 \pm 0.1$ \\
Neurokinin A & 9 & $0.69 \pm 0.13$ & $5.1 \pm 0.2$ \\
& 8 & $0.74 \pm 0.12$ & $6.0+0.6$ \\
& 10 & $0.78 \pm 0.07$ & $4.1 \pm 0.1$ \\
CGRP & 9 & $0.71 \pm 0.02$ & $4.5 \pm 0.4$ \\
& 8 & 0.57 & $9.8 \pm 1.6^{a}$ \\
& 9 & $0.77 \pm 0.10$ & $4.9 \pm 0.1$ \\
5-HT & 8 & $0.66 \pm 0.14$ & $3.9 \pm 0.5$ \\
& 7 & 0.74 & $4.1 \pm 0.3$ \\
& 8 & & $6.1 \pm 2.5$ \\
Bradykinin & 7 & $0.67 \pm 0.06$ & $5.0 \pm 0.7$ \\
& 6 & $0.74 \pm 0.08$ & $8.7 \pm 1.8^{a}$ \\
Histamine & 7 & $0.74 \pm 0.11$ & $4.1 \pm 0.6$ \\
& 6 & $0.75 \pm 0.06$ & $6.4 \pm 0.4^{a}$ \\
PGE 2 & 6 & $0.81 \pm 0.14$ & $5.2 \pm 0.6$ \\
& 5 & 0.56 & $12.2 \pm 1.0^{a}$ \\
& 7 & $0.67 \pm 0.16$ & $5.3 \pm 0.9$ \\
& 6 & $0.61 \pm 0.13$ & $5.3 \pm 0.2$ \\
& & &
\end{tabular}

Data are expressed as means \pm SEM.

${ }^{a} p<0.01$ as compared to control. 
A.

DURA

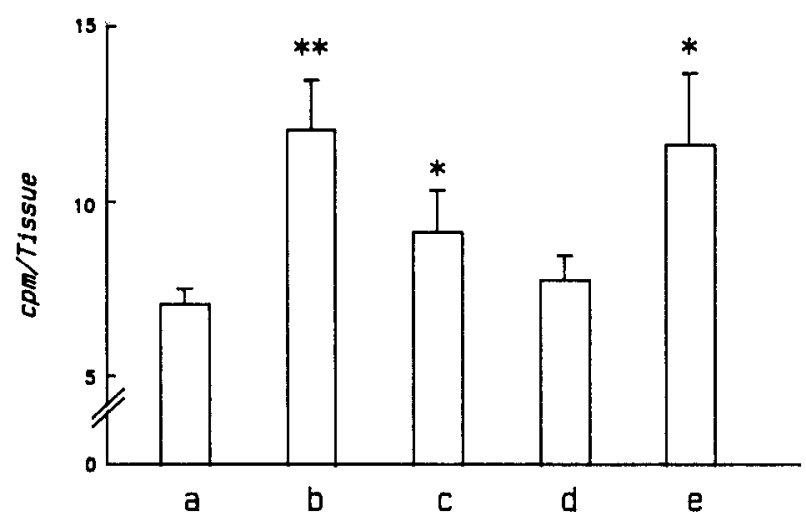

B.

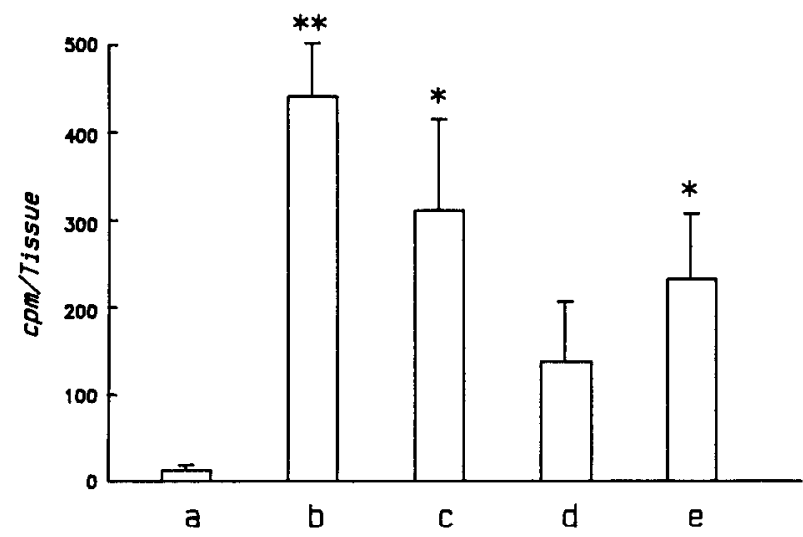

Figure 6. Extravasation of ${ }^{125}$ I-BSA in the dura $(A)$ and in the conjuctiva $(B)$ of guinea pigs increases following antigenic challenge $(a-d)$ or intravenous histamine $(e)$. To examine the effects of immunological stimulation on plasma extravasation, ovalbumin $(20 \mu \mathrm{g} / \mathrm{kg})$ was injected into either nonsensitized $(a)$, previously sensitized $(b)$, or sensitized guinea pigs pretreated with capsaicin $(c)$. In another experiment, sensitized animals were pretreated with cimetidine $(10 \mathrm{mg} / \mathrm{kg})$ and mepyramine $(10 \mathrm{mg} / \mathrm{kg})$ prior to antigen challenge $(d)$. Antigen challenge produces marked extravasation in both the dura and conjunctiva of sensitized animals but not in those pretreated with histamine receptor blockers. Capsaicin pretreatment (desensitization) decreases the response to antigen challenge by $58 \%$ in the dura and by $30 \%$ in the conjunctiva, but these values were not statistically significant. ${ }^{*} p<0.05$, ${ }^{* *} p<0.01$ compared to control animals $(a) . n=4-8$ in each group.

developed extravasation, whereas the temporalis muscle did following high concentrations of intravenous histamine, 5-HT, BK, and NKA. No single explanation is adequate to account for these differences. $\Lambda \mathrm{t}$ least 3 components are important to the phenomenon of neurogenic extravasation: the vessel, the perivascular nerves, and local mast cells, and as noted, the dura contains all three. Clearly, the vessel and related nerves represent the essential components. We believe that the reduced signal reflects mainly the relatively avascular nature of the dura. Similarly, the marked extravasation observed in the conjunctiva and cutaneous tissues probably reflects their greater vascularity. Alternatively, extracranial cutaneous vessels may possess a denser sensory innervation. Vessels that possess a sparse innervation such as those in striated muscle (McMahon et al., 1984) demonstrate a poor response. The temporal artery contains relatively few SP-containing axons and a greater proportion of CGRPcontaining fibers (Uddman et al., 1986). Such an arrangement might also explain the poor response observed in muscle. Paradoxically, pial vessels, which possess a rich innervation by sensory fibers (including those containing tachykinins), demonstrate no neurogenically mediated extravasation. In this case, it is likely that the tight endothelial junctions (comprising the blood-brain barrier) act as a physical barrier to extravasation from the pial circulation. Whether neurogenically mediated lcakage might occur following disruption of the blood-brain barrier remains to be established.

The striking differences in magnitude and threshold of the dural response induced by SP compared to that of capsaicin merits comment, particularly since capsaicin is presumed to work by the release of multiple transmitters, including SP, from perivascular fibers. First, capsaicin appears to show no dosedependent effect in the dura, probably a reflection of a dural threshold dose that approximates the lethal dose. Second, even when administered in higher amounts in vitro $\left(10^{-5} \mathrm{M}\right)$, capsaicin releases only a tiny fraction (about $1.0 \%$ ) of total transmitter pools (Jessel and Iversen, 1977; Moskowitz et al., 1983). Furthermore, since a certain degree of degradation is likely following release from adventitial nerve fibers, the total amount of transmitter reaching its ultimate receptor site on the endothelium would be extremely low. A further possibility is that capsaicin may also corelease an as yet unrecognized antagonist compound.

\section{Non-neurogenically mediated plasma extravasation}

The extravasation demonstrated in the dura following intravenous injection of 5-HT, BK, or histamine was not dependent upon the presence of capsaicin-sensitive fibers. It is possible that this non-neurogenic inflammation may occur by receptormediated mechanisms residing on the endothelium and/or by release of mediators from the vessel wall (e.g., from mast cells). There is some evidence to suggest that endothelial receptor occupation may trigger a cascade of biochemical and physiological events which could lead to formation of interendothelial cell gaps and leakage of macromolecules (Miller and Sims, 1986). These events might include calcium entry, formation of prostaglandins and lipoxygenase products, and generation of free radicals (Kontos et al., 1984). In as much as protein leakage occurs within the venules (Majno and Palade, 1961; Majno et al., 1961), it is unlikely that vascular smooth muscle is involved in any direct way. Similar mechanisms may take place in the dura since venules are the site of leakage in this tissue as well (Gabbiani et al., 1970). Whether the venule leaks protein following neurogenic activation and whether leakage occurs from the vaso vasorum of the meningeal arteries remain to be determined in this tissue.

\section{Immunologically induced plasma extravasation}

Sensitized guinea pigs consistently developed marked extravasation in the dura and conjunctiva but not in the brain following challenge with ovalbumin. Again, the response in the conjunctiva was significantly greater than in the dura. The finding that this leakage was abolished by pretreatment with $\mathrm{H} 1$ and $\mathrm{H} 2$ blockers emphasizes the central role of histamine and suggests that, at least in immunologically mediated extravasation, the mast cell may play a very important role (Kiernan, 1975; Lem- 
beck and Holzer, 1979; Saria et al., 1983). Capsaicin pretreatment had little effect on conjuctival leakage but resulted in a $58 \%$ reduction in the amount of extravasation in the dura, a value which was not statistically significant. Though all sensitized animals demonstrated extravasation, the magnitude of the response not unexpectedly showed wide variation. The failure of capsaicin to influence this response is possibly a reflection of this variation. Nonetheless, our findings suggest the need for additional experiments to clarify this point.

\section{Possible pathophysiological implications of neurogenically mediated inflammation in the dura}

The possibility that neurogenic inflammation may play an important role in the pathogenesis of migraine and cluster headache has been suggested (Chapman et al., 1961; Moskowitz et al., 1979; Hardebo, 1984; Moskowitz, 1984). Although neurogenic inflammation has not been studied in the human dura as yet, the constellation of pro-inflammatory peptides that reside in human ccphalic vesscls (Edvinsson and Uddman, 1982; Jansen et al., 1986; Saito et al., 1987) renders the concept all the more plausible. Indeed, neurogenic inflammation has been observed in human facial skin following trigeminal stimulation. Coin-sized areas of intense vasodilation develop with thermal or electrical stimulation (Sweet and Wepsic, 1974; Drummond et al., 1983). These changes parallel the local increases in blood flow and extravasation within the appropriate receptive field following electrical stimulation of the rat trigeminal ganglia (Jancso-Gabor and Szolcsanyi, 1972) or following electrical stimulation of the distal cut end of the mental nerve (Couture and Cuello, 1984). Regarding headaches, some indirect evidence for the potential importance of neurogenic inflammation is provided by the utility of antiinflammatory agents in the treatment of these conditions (Fozard, 1975).

The studies reported herein demonstrate that nerve fibers in the dura are indeed capable of responding to a wide range of stimuli to produce leakage of plasma proteins. Whether vasodilation occurs concomitantly has yet to be determined. Our recent data showing that administration of ergotamine or dihydroergotamine dramatically blocks neurogenic extravasation within the dura (Moskowitz et al., 1987) suggests that dural neurogenic inflammation may provide a model useful for the investigation of the pathogenesis of headaches and hclpful for rational drug development.

\section{References}

Andersson, P. (1980) Antigen-induced bronchial anaphylaxis in actively sensitized guinea-pigs. Pattern of response in relation to immunization regimen. Allergy 35: 65-71.

Bill, A., J. Stjernschantz, A. Mandahl, E. Brodin, and G. Nilsson (1979) Substance P: Release on trigeminal nerve stimulation. Effects in the eye. Acta Physiol. Scand. 106: 371-373.

Brain, S. D., T. J. Williams, J. R. Tippins, H. R. Morris, and I. MacIntyre (1985) Calcitonin gene-related peptide is a potent vasodilator. Nature 313: 54-56.

Chapman, L. F., A. Ramos, H. Goodell, and H. G. Wolff (1961) Neurohumoral features of afferent fibers in man. Arch. Neurol. 4: 617650.

Couture, R., and A. C. Cuello (1984) Studies on the trigeminal antidromic vasodilatation and plasma extravasation in the rat. J. Physiol. (Lond.) 346: 273-285.

Dalsgaard, C.-J., A. Haegerstrand, E. Theodorsson-Norheim, E. Brodin, and T. Hökfelt (1985) Neurokinin A-like immunoreactivity in rat primary sensory neurons; coexistence with substance P. Histochemistry $83: 37-39$.
Drummond, P. D., A. Gonski, and J. W. Lance (1983) Facial flushing after thermocoagulation of the gasserian ganglion. J. Neurol. Neurosurg. Psychiatr. 46: 611-616.

Edvinsson, L., and R. Uddman (1982) Immunohistochemical localization and dilatatory effect of substance $P$ on human cerebral vessels. Brain Res. 232: 466-471.

Edvinsson, L., J. Cervos-Navarro, L. I. Larsson, C. H. Owman, and A. L. Ronnberg (1977) Regional distribution of mast cells containing histamine, dopamine, or 5-hydroxytryptamine in the mammalian brain. Neurology $27: 878-883$.

Fozard, J. R. (1975) The animal pharmacology of drugs used in the treatment of migraine. J. Pharm. Pharmacol. 27: 297-321.

Gabbiani, G., M. C. Badonnel, and G. Majno (1970) Intra-arterial injections of histamine, serotonin, or bradykinin: A topographic study of vascular leakage. Proc. Soc. Exp. Biol. Med. 135: 447-452.

Gamse, R., and A. Saria (1985) Potentiation of tachykinin-induced plasma protein extravasation by calcitonin gene related peptide. Eur. J. Pharmacol. 114: 61-66.

Gamse, R., P. Holzer, and F. Lembeck (1980) Decrease of substance $P$ in primary afferent neurones and impairment of neurogenic plasma extravasation by capsaicin. Br. J. Pharmacol. 68: 207-213.

Hanko, J., J. E. Hardebo, J. Kahrstrom, C. Owman, and F. Sundler (1985) Calcitonin gene-related peptide is present in mammalian cerebrovascular nerve fibers and dilates pial and peripheral arteries. Neurosci. Lett. 57: 91-95.

Hardebo, J. E. (1984) The involvement of trigeminal substanced $P$ neurons in cluster headache. An hypothesis. Headache 24: 294-304.

Hua, X.-Y., J. M. Lundberg, E. Theodorsson-Norheim, and E. Brodin (1984) Comparison of cardiovascular and bronchoconstrictor effects of substance P, substance $K$ and other tachykinins. Naunyn-Schmiedeberg's Arch. Pharmacol. 328: 196-201.

Hua, X.-Y., A. Saria, R. Gamse, E. Theodorrson-Norheim, E. Brodin, and J. M. Lundberg (1986) Capsaicin induced release of multiple tachykinins (substance $P$, neurokinin $A$ and eledoisin-like material) from guinea-pig spinal cord and ureter. Neuroscience 19: 313-319.

Jancso, G., E. Kiraly, and A. Jancso-Gabor (1977) Pharmacologically induced selective degeneration of chemosensitive primary sensory neurones. Nature 270:741 743.

Jancso, N., A. Jancso-Gabor, and J. Szolcsanyi (1967) Direct evidence for neurogenic inflammation and its prevention by denervation and by pretreatment with capsaicin. Br. J. Pharmacol. Chemother. 31 : 138-151.

Jancso-Gabor, A., and J. Szolcsanyi (1972) Neurogenic inflammatory responses. J. Dent. Res. 51: 264-269.

Jansen, I., R. Uddman, M. Hocherman, R. Ekman, K. Jensen, J. Olesen, P. Stiernholm, and L. Edvinsson (1986) Localization and effects of neuropeptide $Y$, vasoactive intestinal polypeptide, substance $P$, and calcitonin gene-related peptide in human temporal arteries. Ann. Neurol. 20:496-501.

Jessel, T. M., and L. L. Iversen (1977) Opiate analgesics inhibit substance $P$ release from rat trigeminal nucleus. Nature 268: 549-551.

Kenins, P., J. V. Hurley, and C. Bell (1984) The role of substance P in the axon reflex in the rat. Br. J. Dermatol. 111: 551-559.

Kiernan, J. A. (1975) A pharmacological and histological investigation of the involvement of mast cells in cutaneous axon reflex vasodilatation. Q. J. Exp. Physiol. 60: 123-130.

Kontos, H. A., E. P. Wei, J. T. Povlishock, and C. W. Christman (1984) Oxygen radicals mediate the cerebral arteriolar dilation from arachidonate and bradykinin in cats. Circ. Res. 55: 295-303.

Lembeck, F., and J. Donnerer (1985) Opioid control of the function of primary afferent substance P fibers. Eur. J. Pharmacol. 114: 241246.

Lembeck, F., and P. Holzer (1979) Substance Pas neurogenic mediator of antidromic vasodilation and neurogenic plasma extravasation. Naunyn-Schmiedeberg's Arch. Pharmacol. 310: 175-183.

Lembeck, F., J. Donnerer, and L. Bartho (1982) Inhibition of neurogenic vasodilatation and plasma extravasation by substance $P$ antagonists, somatostatin and [D-met ${ }^{2},-$ pros $\left.^{5}\right]$ enkephalinamide. Eur. J. Pharmacol. 85: 171-176.

Lundberg, J. M., and A. Saria (1982) Capsaicin-sensitive vagal neurons involved in control of vascular permeability in rat trachea. Acta Physiol. Scand. 115: 521-523.

Lundberg, J. M., E. Brodin, X.-Y. Hua, and A. Saria (1984) Vascular permeability changes and smooth muscle contraction in relation to capsaicin-sensitive substance $P$ afferents in the guinea-pig. Acta Physiol. Scand. 120: 217-227. 
Lundblad, L., A. Anggard, and J. M. Lundberg (1983a) Effects of antidromic trigeminal nerve stimulation in relation to parasympathetic vasodilation in cat nasal mucosa. Acta Physiol. Scand. 119:713.

Lundblad, L., A. Saria, J. M. Lundberg, and A. Anggard (1983b) Increased vascular permeability in rat nasal mucosa induced by substance $P$ and stimulation of capsaicin-sensitive trigeminal neurons. Acta Otolaryngol. 96: 479-484.

Majno, G., and G. E. Palade (1961) Studies on inflammation. I. The effect of histamine and serotonin on vascular permeability: An electron microscopic study. J. Biophys. Biochem. Cytol. 11: 571-605.

Majno, G., G. E. Palade, and G. I. Schoefl (1961) Studies on inflammation. II. The site of action of histamine and serotonin along the vascular tree: A topographic study. J. Biophys. Biochem. Cytol. 11. 607-626.

Mayberg, M. R., R. S. Langer, N. T. Zervas, and M. A. Moskowitz (1981) Perivascular meningeal projections from cat trigeminal ganglia: Possible pathway for vascular headache in man. Science 213: 228-230.

Mayberg, M. R., N. T. Zervas, and M. A. Moskowitz (1984) Trigeminal projections to supratentorial pial and dural blood vessels in cats demonstrated by horseradish peroxidase histochemistry. J. Comp. Neurol. 223: 46-56.

McMahon, S. B., E. Sykcva, P. D. Wall, C. J. Woolf, and S. J. Gibson (1984) Neurogenic extravasation and substance $P$ levels are low in muscle as compared to skin in the rat hindlimb. Neurosci. Lett. 52: 235-240.

McNaughton, F. L. (1938) The innervation of the intracranial blood vessels and dural sinuses. In The Circulation of the Brain and Spinal Cord, S. Cobb, A. M. Frantz, W. Penfield, and H. A. Riley, eds., pp. 178-200, Williams \& Wilkins, Baltimore.

Miller, F. N., and D. E. Sims (1986) Contractile elements in the regulation of permeability. Fed. Proc. 45: 84-88.

Moskowitz, M. A. (1984) The neurobiology of vascular head pain. Ann. Neurol. 16: 157-168.

Moskowitz, M. A., J. F. Reinhard, Jr., J. Romero, E. Melamed, and D. J. Pettibone (1979) Neurotransmitters and the fifth cranial nerve: Is there a relation to the headache phase of migraine? Lancet $2: 883-$ 885 .

Moskowitz, M. A., M. Brody, and L.-Y. Liu-Chen (1983) In vitro release of immunoreactive substance $P$ from putative afferent nerve endings in bovine pia arachnoid. Neuroscience 9: 809-814.

Moskowitz, M. A., S. Markowitz, and K. Saito (1987) Ergot alkaloids specifically block neurogenically-induced plasma extravasation in rat dura: Mechanism of action in vascular headaches. Fed. Proc. 46: 634.

O'Connor, T. P., and D. van der Kooy (1986) Pattern of intracranial and extracranial projections of trigeminal ganglion cells. J. Neurosci. 6: 2200-2207.

Olsson, Y. (1968) Mast cells in the nervous system. Int. Rev. Cytol. 24: $27-70$.

Ray, B. S., and H. G. Wolff (1940) Experimental studies on headache. Pain sensitive structures of the head and their significance in headache. Arch. Surg. 41: 813-856.

Rosell, S., L. Olgart, B. Gazelius, P. Panopoulos, K. Folkers, and J. Horig (1981) Inhibition of antidromic and substance P-induced vasodilation by a substance P antagonist. Acta Physiol. Scand. 111. $381-382$.

Saito, K., S. Greenberg, and M. A. Moskowitz (1987) Trigeminal origin of beta-preprotachykinin products in feline pial blood vessels. Neurosci. Lett. 76: 69-73.

Saria, A., and J. M. Lundberg (1983) Evans blue fluorescence: Quantitative and morphological evaluation of vascular permeability in animal tissues. J. Neurosci. Methods 8: 41-49.

Saria, A., J. M. Lundberg, G. Skofitsch, and F. Lembeck (1983) Vascular protein leakage in various tissues induced by substance $P$, capsaicin, bradykinin, serotonin, histamine and by antigen challenge. Naunyn-Schmiedeberg's Arch. Pharmacol. 324: 212-218.

Saria, A., R. Gamse, J. Petermann, J. A. Fischer, E. TheodorrsonNorheim, and J. M. Lundberg (1986) Simultaneous release of several tachykinins and calcitonin gene-related peptide from rat spinal cord slices. Neurosci. Lett. 63: 310-314.

Steiger, H. J., J. M. Tew, and J. T. Keller (1982) The sensory representation of the dura mater in the trigeminal ganglion of the cat Neurosci. Lett. 31: 231-236.

Stricker, S. (1876) Untersuchungen uber die gefassnerven-wurzeln des ischiadicus. Sitz-Ber Kaiserl Akad Wiss (Wien) 3: 173-185.

Sweet, W. H., and J. G. Wepsic (1974) Controlled thermocoagulation of trigeminal ganglion and rootlets for differential destruction of pain fibers. Part 1: Trigeminal neuralgia. J. Neurosurg. 40: 143-156.

Uddman, R., L. Edvinsson, I. Jansen, F. Gjerris, K. Jensen, J. Olesen, and $F$. Sundler (1986) Peptide-containing nerve fibers in human extracranial tissue: A morphological basis for neuropeptide involvement in extracranial pain? Pain 27: 391-399.

Von Lushka, H. (1850) Die Nerven in der Harten Hirnhaut, Laupp, Tubingen. 